\title{
Rendimentos do trabalho de homens e mulheres na crise (Brasil 2014-2017)
}

\section{Adriana R. de Mendonça*, Eugenia T. Leone}

\section{Resumo}

Análise dos possíveis efeitos de queda da atividade econômica sobre os rendimentos do trabalho em salário mínimo, conforme as posições na ocupação e sexo dos trabalhadores, comparando os últimos trimestres de 2014, 2015, 2016, 2017 e 2018, com o objetivo de analisar os possíveis impactos de um período de recessão econômica sobre essas variáveis.

\section{Palavras-chave:}

rendimentos, crise, trabalho

\section{Introdução}

Pesquisa com o objetivo de analisar os possíveis efeitos negativos de um período de queda da atividade econômica no país - 2014 a 2018 - sobre os rendimentos provenientes do trabalho de homens e mulheres que fazem parte da atividade econômica, com ênfase nas transformações dos rendimentos do trabalho conforme as posições de ocupação e sexo dos trabalhadores.

As etapas de elaboração do trabalho constituíram-se por revisão bibliográfica do tema, desenho da conjuntura macroeconômica do período especificado e elaboração e análise de tabelas com indicadores de mercado de trabalho.

O panorama macroeconômico é apresentado através das seguintes variáveis: PIB, inflação, e taxa básica de juros. Já o desempenho do mercado de trabalho, por sua vez, é apresentado pelas seguintes variáveis: rendimentos do trabalho em salários mínimos, posição da ocupação e sexo. Sendo que as tabelas para análise do mercado de trabalho foram elaboradas com base nos microdados da Pesquisa Nacional por Amostra de Domicílios Contínua Trimestral, disponibilizados pelo IBGE e trabalhados em software estatístico (SPSS).

Fez-se uma análise comparativa das categorias de posição de ocupação e rendimento em salário mínimo, separados por sexo, dos últimos trimestres dos anos de 2014, 2015, 2016, 2017 e 2018 com o objetivo de observar e analisar os possíveis impactos de um período de crise nessas variáveis, além disso, fez-se uma análise de importantes indicadores de mercado de trabalho no período, conforme tabelas abaixo:

\begin{tabular}{|c|c|c|c|c|c|c|c|c|c|c|}
\hline & therem 2014 & es & ${ }^{2015}$ & tas & ${ }_{\text {Hamon }}{ }^{2016}$ & ther & thenen & Mats & thange 2018 & Meser \\
\hline 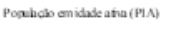 & 40,95 & $49 \pi \times$ & $40,8 \%$ & 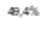 & 41006 & $49,2 \mathrm{x}$ & $41,0 \%$ & $485 \%$ & $41.1 \%$ & $48, x$ \\
\hline & 29.36 & $251 \%$ & 29,65 & $2,3 \%$ & 295\% & 25.A6 & 29.5\% & $25,6 \%$ & $294 \%$ & $8, \pi$ \\
\hline 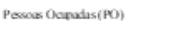 & 27.96 & $232 \%$ & 27,36 & $22,6 \%$ & $254 \%$ & 21,96 & $25,4 \%$ & 22,25 & $255 \%$ & $22 \pi$ \\
\hline sencrespda (1) & $1,6 \mathrm{k}$ & $1.9 \%$ & $2.3 \%$ & $2, \pi \pi$ & $31 \%$ & 3.56 & $3,1 \%$ & $3,4 x$ & $30 \%$ & 3,30 \\
\hline al & 1005 & $100 \%$ & $100 \%$ & $100 \%$ & $200 \%$ & 1000 & $100 \%$ & $1000 \%$ & $200 \%$ & 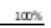 \\
\hline
\end{tabular}

\begin{tabular}{|c|c|c|c|c|c|c|c|c|}
\hline & $\begin{aligned} 204 \\
\text { theren }\end{aligned}$ & ter & 2015 & Meler & ${ }_{\text {Hemano }}^{2016}$ & Hos & ${ }_{\text {Hhorm }}^{2017}{ }^{2017 \text { Mer }}$ & Hamen $^{2018}$ Mins \\
\hline Taxis de Patichucio & $722 \%$ & $50,6 \%$ & $72,6 \%$ & $72,6 \%$ & $720 \%$ & 51,56 & 72,086 & 72.36 \\
\hline Taxis de Oanpusio & $682 \%$ & $45,7 \%$ & $67,0 \%$ & $45,8 \%$ & 543\% & $4.5 \%$ & $64.5 \%$ & 5436 \\
\hline Taus de Mesermoeno & $36 \%$ & $7, \pi \%$ & $7,7 \%$ & 10.65 & $107 \mathrm{~s}$ & 13.85 & 10.5\% & 10.25 \\
\hline
\end{tabular}

\section{Resultados e Discussão}

Pela pesquisa elaborada, foi possível verificar que as alterações no quadro da economia internacional provocaram uma desaceleração do crescimento do PIB, principalmente desde 2011.

A política para sustentar esse crescimento, por meio do estímulo ao investimento privado, mostrou-se ineficaz e as alterações implantadas nessa política no ano de 2015 provocaram a queda na atividade econômica neste ano e também no ano seguinte que, por sua vez, impactou tanto na composição de participação das posições ocupadas no mercado de trabalho quanto no rendimento dos trabalhadores.

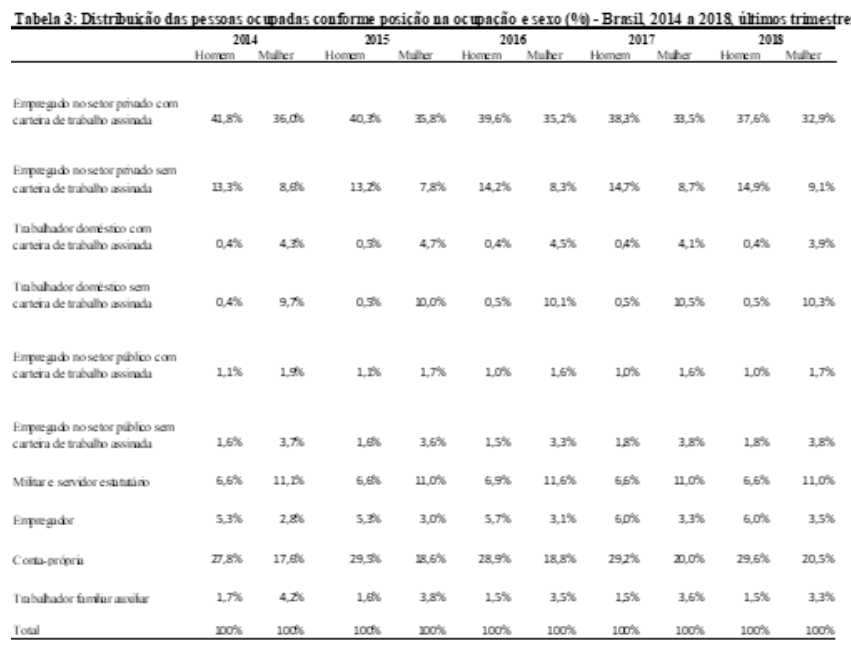

\section{Conclusões}

O processo de queda de atividade econômica provoca, mesmo que com um lapso temporal de resposta, impactos na composição ocupada mercado de trabalho e nos rendimentos da população.

\section{Agradecimentos}

Agradeço ao $\mathrm{CNPq}$ pela disponibilização da Bolsa de fomento a este trabalho e a minha orientadora pela grande oportunidade de aprendizado.

BRASIL. IBGE. Pesquisa Nacional por Amostra de Domicílios Contínua Trimestral, 2018. Disponível em

<ftp://ftp.ibge.gov.br/Trabalho_e_Rendimento/Pesquisa_Nacional_por_Amost ra_de_Domicilios_continua/Trimestral/Microdados> 